\title{
ASYMMETRICAL FAULT DETECTION IN DE-ENERGIZED DISTRIBUTION FEEDER
}

\author{
Gajanan Vedpathak $^{1}$, Ajay Kashid ${ }^{2}$, VRSV Bharath Pulavarthi ${ }^{3}$ \\ ${ }^{1}$ B.Tech Student, Electrical Department, Rajarambapu Institute Technology, India \\ ${ }^{2}$ B.Tech Student, Electrical Department, Rajarambapu Institute Technology, India \\ ${ }^{3}$ Assistant Professor, Electrical Department, Rajarambapu Institute Technology, India
}

\begin{abstract}
After maintenance or repairing of the de-energized distribution feeder there is need of safely energizing of feeder for the utility's safety. The safely energizing can be done by determining the fault exists on the distribution system before energizing the system again. The fault detection in de-energized distribution feeder is more difficult than the energized distribution feeder since it requires the system level voltage production and execution to the downstream. Here we implemented an asymmetrical fault detection method to detect the fault before re-energizing the distribution feeder. A controllable signal is feed into de-energized distribution feeder using a thyristor based device to generate the electrical response. The strength of signal can be adjusted from low to high to detect low impedance fault at the beginning, since the maximum faults on distribution system are low impedance faults. A low strength signal may act as an alarm to the personnel or animal in contact with the live part of the system so that they can get away from the system to avoid getting sudden electric shock. Also the major faults on distribution systems are asymmetrical faults so it is necessary to identify and detect the asymmetrical faults before Re-energizing the feeder. The detection and classification of different asymmetrical faults is also explained in this paper. For the determination of the faults we are analyzing the voltage and current signals of the downstream feeder. The fault detection algorithm and control strategies of thyristors are also described for different faults and analyzed by using computer simulation in MATLAB.
\end{abstract}

Keywords: Fault Detection, Fault Classification, De-Energized Distribution Feeder.

\section{INTRODUCTION}

The distribution feeder de-energizing is required to repair or maintain the downstream line or it is de-energized due to the abnormal weather conditions such as storms or rainy atmosphere. In these situations, animal or human being may come in contact with the conductor of distribution feeder. If reclosing action is done in such a case, then it leads to harmful effects on them. The extreme case is death of human. Therefore to avoid this and to detect the different asymmetrical faults on distribution system we are proposing a new scheme which will helpful for analyzing the faults before reclosing the feeder by sending the controllable signals to the downstream line which are generated by the thyristor based device. In a de-energized system fault detection is more difficult than fault detection in an energized system because it needs the voltage signal production and executed it to the downstream line. We can generate the signal by using the capacitor by charging and discharging and by connecting it into the circuit but it is not able to reach to the very high voltage. Another method is, we can take energy from upstream line to generate the signal which overcomes the need of additional power source. Inrush current is injected into the downstream line before inserting the series impedance because of auto-Recloser. Main drawback of all above devices is that they cannot detect all faults in only one device. Recently, to minimize the inrush current a pulse-Recloser technique is elaborated, but after the use we have to change an existing breaker or Recloser by new one. This can be costly.
The above techniques are having some limitations, so we are proposing the thyristor based device for detecting the faults in a de-energized distribution feeder. The parallel connection of the device is made with a Recloser to inject the adjusted signal by changing the firing angle of thyristor when the system is de-energized.

A low impedance fault is generally a short circuit fault with low resistance. It allows to flow of a large amount of fault current. The high impedance fault is generally an arc fault. It is difficult to detect a high impedance fault by conventional over current protection devices because of low fault current. About $85-98 \%$ faults in power distribution system are low impedance faults and remaining are the high impedance faults which are having a very low percentage.

The major fault detection techniques for high impedance fault detection uses signal generated by an electric arc (harmonic and non-harmonic components). But, before gathering enough information by the detection system to confirm the fault, the arc may vanish. The high impedance fault may occur when a conductor breaks and fall to ground or touches high impedance surfaces like sand or cement. In another case, conductor breaks and touches to tree limbs. Here feeder current increases but not enough to detect by conventional relays. So these types of faults are very dangerous for human life so it is necessary to detect the faults without fail. 
In this paper, we focused on the identification of various types of asymmetrical faults in the distribution line. The faults are classified as symmetrical and asymmetrical faults. The symmetrical fault includes three phase-to-ground fault which occurs rarely on the distribution line as about $5 \%$ only. The asymmetrical fault includes open conductor faults, Single phase-to-ground fault, Phase-to-phase fault and Double phase-to-ground fault. As compared to three phase faults the LG fault causes greater fault current. Also the asymmetrical fault analysis is useful for single-phase switching, relay setting and system stability studies. The possibility of two or more simultaneous faults i.e. crosscountry faults on a power system is rare therefore it is ignored.

\section{BASICS}

The proposed scheme has been shown by single line representation in fig a. This consists of Thyristor Bridge in parallel with Recloser or circuit breaker connected by using a switch such that the switch is open during the regular condition and operator can connect the thyristor circuit after repair or maintenance on the feeder to check whether the fault is present or not in the de-energized line. The stepdown transformer is connected after the switch to step-down the system voltage to the thyristor operating voltage so that it will reduce the cost and the size of the thyristors to be used. The thyristor circuit is connected between step-down and step-up transformer. The step-up transformer converts the thyristor operating voltage to the voltage level of the distribution system. After connecting the thyristor circuit to the upstream energized line, the thyristors are triggered according to the control modes as given in the table 1. The current and voltage signals of the feeder are measured and analysed by using signal detector at point $\mathrm{M}$ as shown in the fig a. The thyristor current and voltage waveforms and measured current and voltage waveforms are shown in fig $b$.

As discussed before, the thyristor generated controlled signal is injected in the de-energized distribution feeder. For this purpose an energized upstream is connected to the controlled thyristor through step down transformer. To distinguish different types of faults the signal must be adjusted to the large range of magnitude strength. Formerly, a low strength signal is generated to identify the low impedance fault. A low strength signal is acts as an alarm to the human or animals in contact with the feeder conductors so that they can get away from the live conductor to avoid the injury. After that by decreasing the firing angle of thyristor we are increasing the strength of signal in the feeder for the high impedance fault detection.

\section{CONTROL STRATEGY}

As we are considering for the three-phase four wire distribution system, the fault may be asymmetrical or symmetrical in nature such as either phase to phase or phase to ground. The detection and classification of faults in a one device are possible by this scheme by just observing the magnitudes of current and voltage signals at point $\mathrm{x}$.

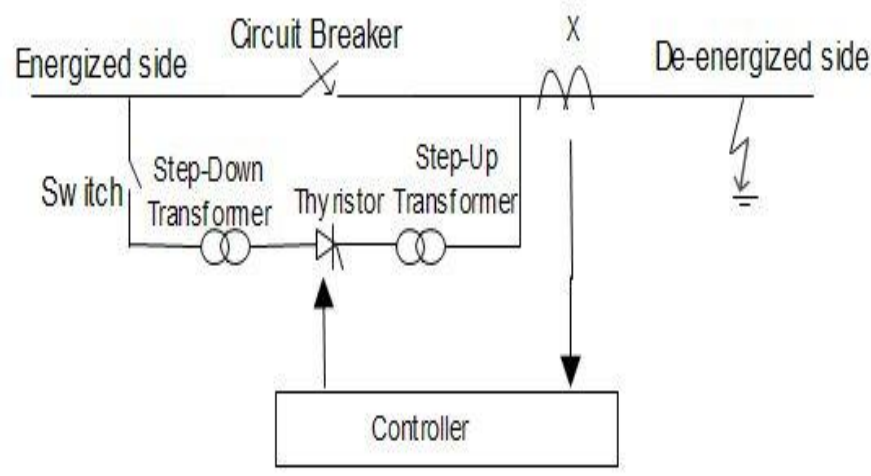

Fig.1 Single line representation of thyristor based device.
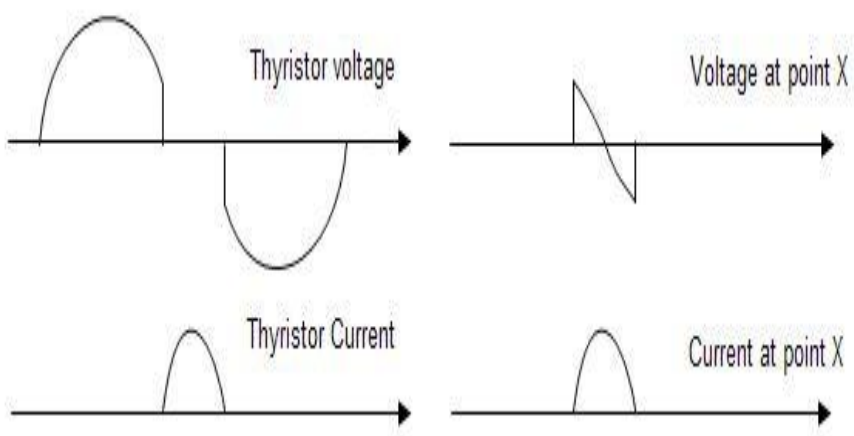

Fig.2 Waveforms of voltages and currents of thyristors and at point $\mathrm{X}$

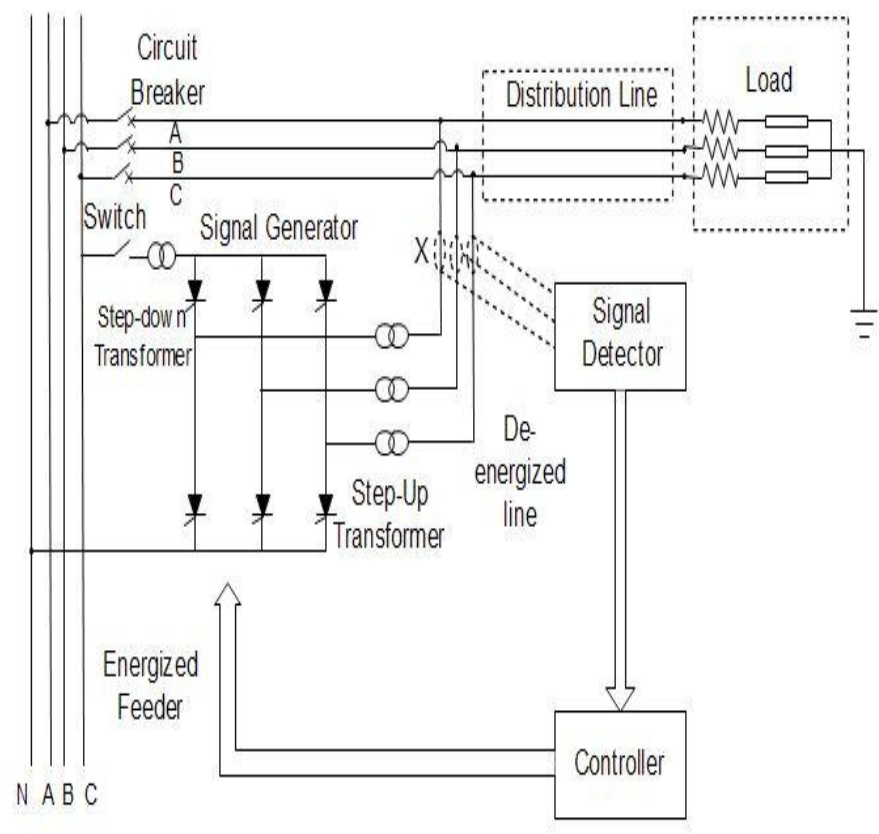

Fig.3 Thyristor-bridge based fault detection method

We inject the detection signal into the De-energized distribution feeder, the current and voltage magnitudes are measured and analysed at point $\mathrm{x}$ through signal detector. Depending upon the magnitude of the measured signal, the classification of different types of fault is done. To identify the type of fault arrangement of different gating signal is 
used. There are two control methods for detecting the phaseto-ground and phase-to-phase fault. As seen from the figure, upper three thyristors are connected to the one phase of the upstream line and lower three thyristors are connected to the neutral of the line.

In the first mode, for detecting the phase to ground fault, only upper three thyristors are to be triggered and all bottom thyristors are off. As the firing angles of the upper thyristors are reduced, the strength of the detection pulse injected in the de-energized distribution feeder is increased to detect the high impedance fault. If the fault is exist between any phase and ground then it will reflect in the magnitude of the current. In the second mode, for phase to phase fault detection there are two steps: first one is that one thyristor from upper group (phase A) and two from bottom group (phase B \& C) are to be triggered for phase A-B \& phase A$\mathrm{C}$ fault detection and in second step one thyristor from upper group (phase B) and one from bottom group (phase C) are triggered to identify the phase B-C fault. This control logic is also explained from the following table 1 which detects all types of faults including three steps.

Table.1 Control Logic for Fault Detection

\begin{tabular}{|l|l|l|}
\hline Steps & Type of fault & $\begin{array}{l}\text { Control strategy } \\
\text { used }\end{array}$ \\
\hline Step 1 & $\begin{array}{l}\text { Single phase-to-ground fault } \\
\text { Double phase-to-ground fault } \\
\text { Three phase-to-ground fault }\end{array}$ & $\begin{array}{l}\text { T1, T3, T6 ON } \\
\text { Others are OFF }\end{array}$ \\
\hline Step 2 & $\begin{array}{l}\text { phase A to phase B fault } \\
\text { phase A to phase C fault }\end{array}$ & $\begin{array}{l}\text { T1, T4, T6 ON } \\
\text { Others are OFF }\end{array}$ \\
\hline Step 3 & phase B to phase C fault & $\begin{array}{l}\text { T3, T6 ON } \\
\text { Others are OFF }\end{array}$ \\
\hline
\end{tabular}

\section{FAULT ANALYSIS}

\subsection{Phase -to-Ground Fault Detection}

As we know that from the statistics the single phase-toground fault in a distribution system is the most common fault which consists around $85 \%$ of the distribution faults and three phase- to-ground fault accounts for $5 \%$.

To identify single phase-to-ground fault we are triggering the upper three thyristors while bottom three thyristors are not triggered and a low strength signal is injected in the feeder

The Unbalanced Phase-to-Ground fault can be detected as per the following criteria:

\section{Step I- (T1, T3, T5 Triggered)}

1) Measure all three phase current magnitudes.

2) Calculation of the injected current magnitude in each phase is done. If magnitudes are identical, then there is no asymmetrical type of fault (or there is a possibility of symmetrical fault LLL-G), if NO then there exist any phaseto -Ground fault.

i) If the magnitude of current in one of the phases is greater than other two current magnitudes, (e.g. $\mathrm{I}_{\mathrm{a}}>\mathrm{I}_{\mathrm{b}} \& \mathrm{I}_{\mathrm{b}}=\mathrm{I}_{\mathrm{c}}$ ) then it indicates that there is a single phase-to-Ground fault and the faulted line is identified (e.g. Phase A to Ground Fault).

ii) If two current magnitudes are equal and greater than the remaining phase current magnitude (e.g. $\mathrm{I}_{\mathrm{a}}=\mathrm{I}_{\mathrm{b}} \& \mathrm{I}_{\mathrm{b}}>\mathrm{I}_{\mathrm{c}}$ ), then it indicates that there is a double-phase to ground fault and then the two faulted lines are identified (e.g. Phase A Phase B to Ground Fault).

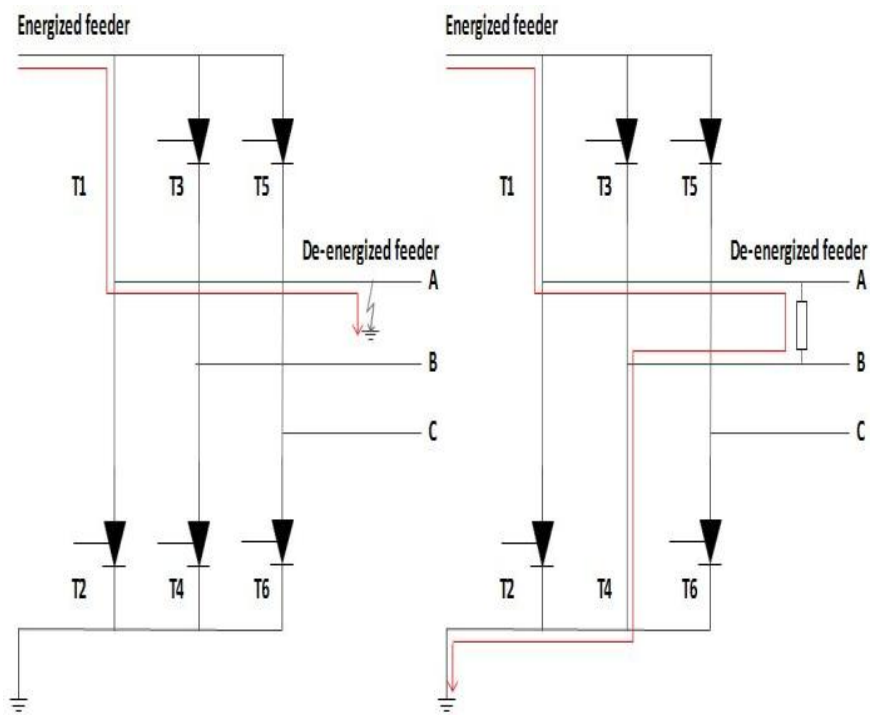

Fig.4 The control logic for Phase-to-Ground and phase-tophase fault detection.

\subsection{Phase-to-Phase fault Detection}

The Phase to Phase fault can be detected as per the following criteria:

\section{Step II- (T1, T4, T6 Triggered)}

1) Measure the phase $B$ and phase $C$ currents magnitude. If $\mathrm{I}_{\mathrm{b}}<0$, then fault present between phase $\mathrm{A}$ and phase $\mathrm{B}$. If $\mathrm{I}_{\mathrm{c}}<0$, then fault present between phase $A$ and phase $C$. If not, then there is no phase to phase fault present i.e. fault between phase $\mathrm{A}$ and other is not present

\section{Step III- (T3, T6 Triggered)}

2) Measure the phase $C$ current magnitude.

If $\mathrm{I}_{\mathrm{C}}<0$, then fault present between phase $\mathrm{B}$ and phase $\mathrm{C}$; If not, then there is no fault present between phase $\mathrm{B}$ and phase C.

All phase-to-phase faults are identified in these two steps i.e. step II and step III.

\section{SYSTEM ANALYSIS}

If we consider the system with zero sequence current injection then system will look like as shown in the fig.5. As we are observing the current magnitudes of the downstream feeder at point $\mathrm{x}$ so that for the fault analysis, we are considering only part after the point $\mathrm{x}$ to the ground since the part before the point $\mathrm{x}$ will be common for healthy and faulty condition. As shown in fig.5 the line and load impedance will form the system impedance. 


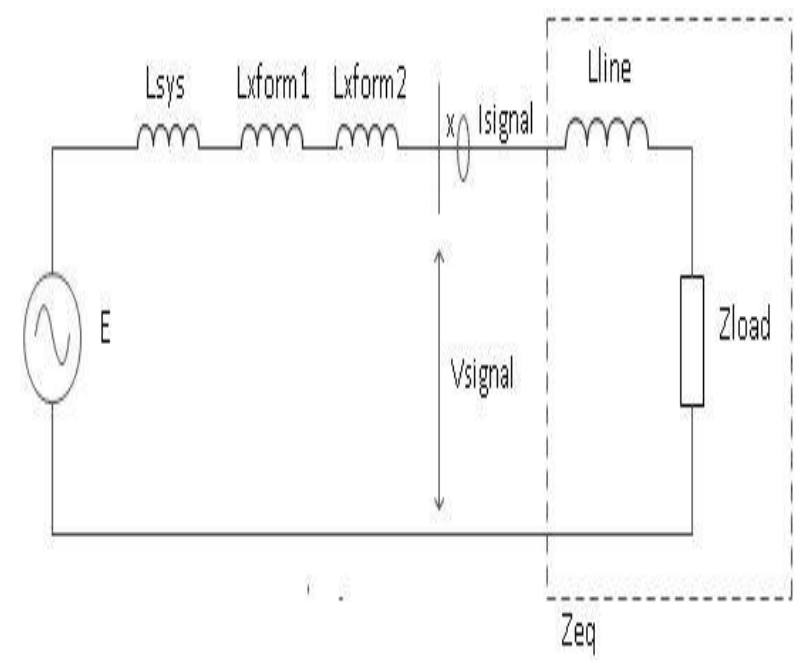

Fig.5 Equivalent circuit diagram for zero sequence current injection

When a single phase to ground fault is occur in the distribution line then distribution line will be separated in two parts as shown in fig. 6 and the ground resistance will come across the line and load impedance, due to the parallel operation of these two resistances the equivalent system impedance will drop down and as the resistance in the respective phase decreases the current in that phase will increases whereas the current magnitudes in other two phases will be same.

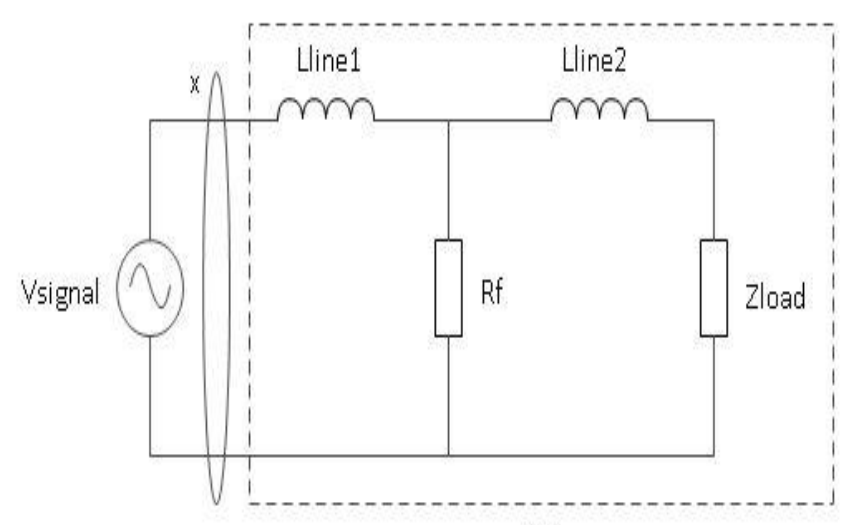

Zeq

Fig.6 Equivalent circuit diagram for single phase-to-Ground fault

When a phase to phase fault is occur in the system then the system will look like as shown in the fig.7 i.e fault resistance will come in series with the one line and this total connection will come across the another line. In this case the fault resistance is very less than that of the load resistance hence system current will pass back through the another line hence the thyristor in the second line will start conducting in the negative half cycle and from this we can detect the faulty phases i.e line1 to line 2 fault. (phase to phase fault)

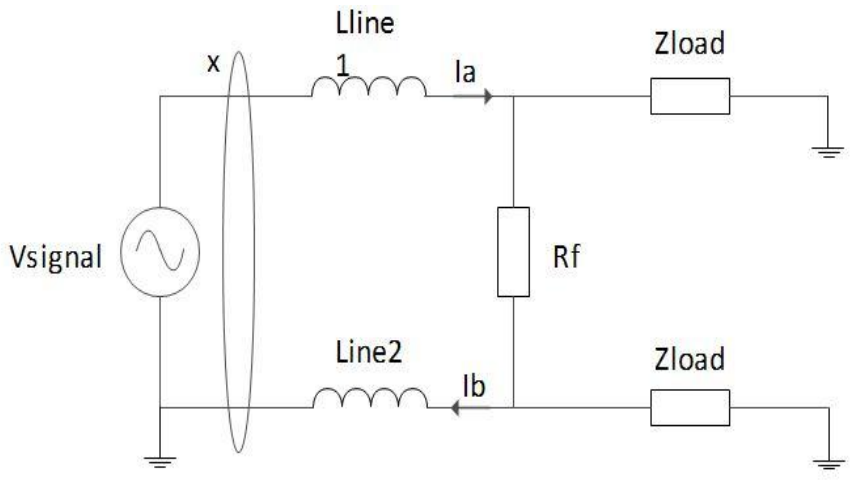

Fig.7 Equivalent circuit diagram for phase-to-phase fault

\section{COMPUTER SIMULATION}

The simulation is done by using MATLAB to perform and verify the analysis mentioned in section 4 . The distribution line rated voltage is $400 \mathrm{~V}$. The parameters considered for constructing the device are as follows:

○ Utility: L-L RMS 400 V, Star-ground connected.

O Transformers:

Step-down Transformer: - Single phase, 230V/12V Stepup Transformer: - Single phase, 12V/230V.

- Feeder:

Both feeder Line 1 and Line 2 are of $1 \mathrm{~km}$ long, the positive sequence $\quad \mathrm{R}_{1}=0.2138 \Omega / \mathrm{km}, \quad \mathrm{X}_{1}=0.3928 \Omega / \mathrm{km}, \quad \mathrm{B}_{1}=$ $4.2315 \mu \mathrm{S} / \mathrm{km}$; the zero sequence $\mathrm{R}_{0}=0.3875 \Omega / \mathrm{km}, \mathrm{X}_{0}=$ $1.8801 \Omega / \mathrm{km}, \mathrm{B}_{1}=1.6058 \mu \mathrm{S} / \mathrm{km}$.

○ Signal generator: Three phase Thyristor Bridge.

- Fault resistance: $0-25 \Omega$, the default resistance $10 \Omega$.

○ Load: Lamp Load. (500 watt)

According to the FIG.8 the thyristor controlled device is connected in parallel with the Recloser through a switch and step down transformer. The bridge is connected to downstream line by step-up transformers. We have connected three separate single phase transformers instead of one three phase transformer because current pulses are not balanced and also to reduce interference between two phases. The firings of thyristors are carried out according to the control logic given in section III. In each step thyristors are fired at an angle near to $170^{\circ}$ and reduced after until the faults are identified.

The current waveforms are shown in the FIG.9 and FIG.10 when there is no fault exists in the system. In step I all upper thyristors are connected to the energized line and signals are injected from all phases. In step II single injected through only phase A and phase B \& $\mathrm{C}$ are connected to neutral. In Step III the signal injected through phase $\mathrm{B}$ and phase $\mathrm{C}$ is connected to neutral. 


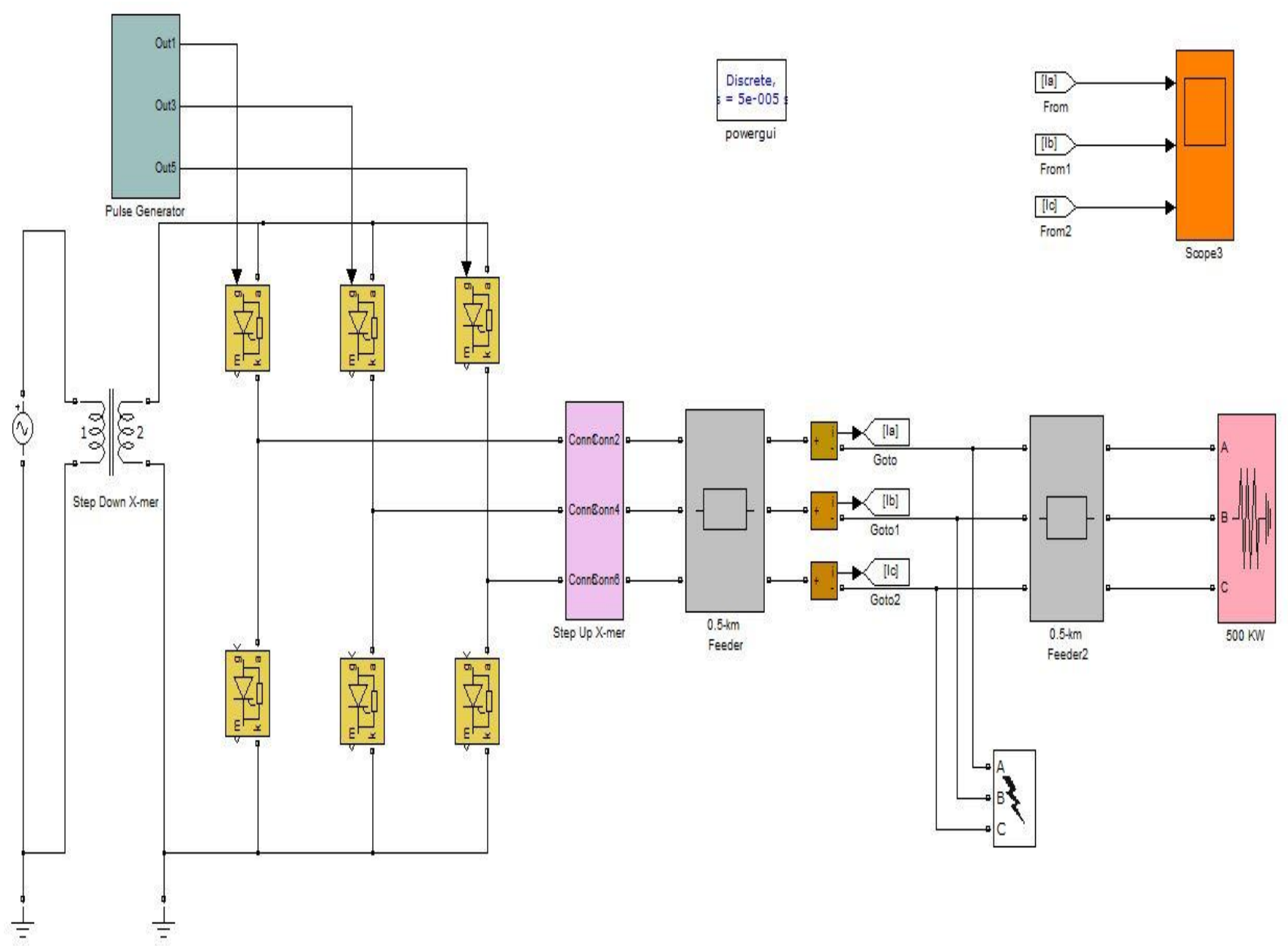

Fig.8 Computer Simulation of proposed thyristor based technique in MATLAB

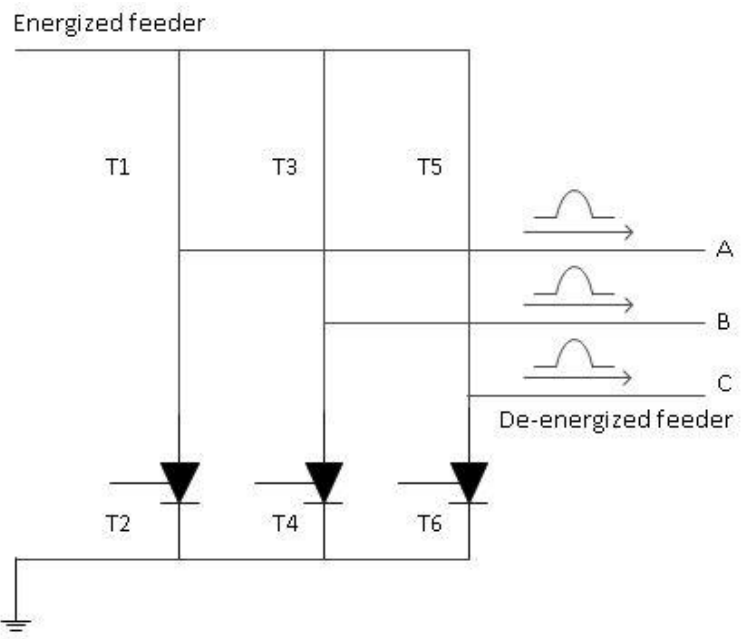

Fig.9 Current waveform with gating control during no fault condition

\subsection{Phase-to-Ground Fault}

In step I, if the phase-to-ground fault exists in the system between phase A to Ground then the current will changes accordingly as shown in FIG.11 and it is greater than the other two phase currents as shown in FIG.12. The phase A to ground fault does not affect on the phase B and phase C.
But the fault current magnitude is depending upon the fault resistance. If the fault resistance is small then the fault current magnitude is more and if the fault resistance increases then the fault current will be having less magnitude.
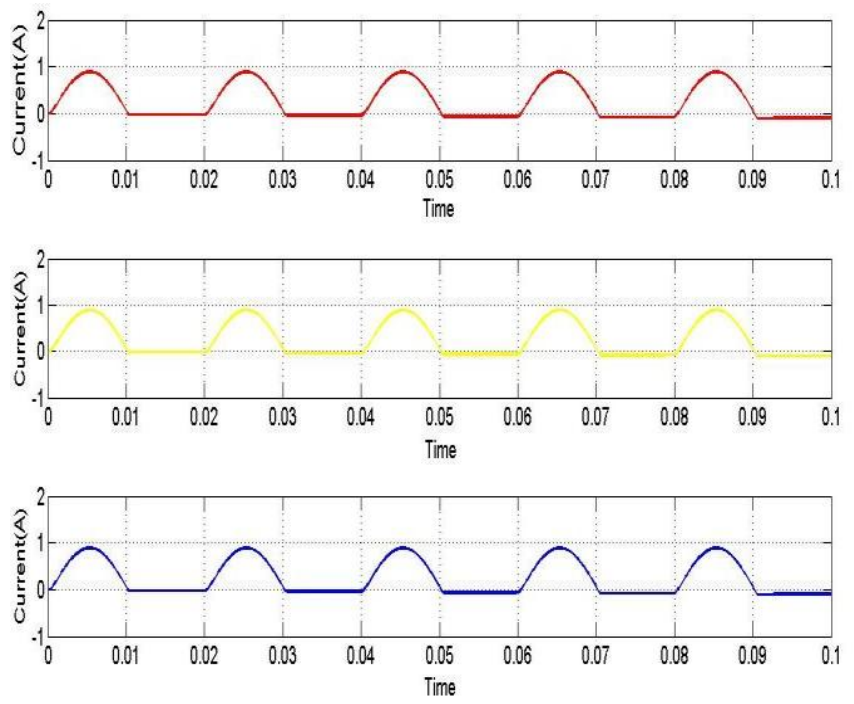

Fig.10 Current waveforms during no fault condition 
We can analyze this in MATLAB by taking different values of fault resistance. For large value of fault resistance the currents in unfaulted phases are comparatively same as faulted phase so the difficulty increases to detect the fault. Therefore firing angle is reduced to identify the difference in magnitudes of faulted and unfaulted current magnitudes.

\subsection{Phase-to-Phase Fault}

If a fault occurs between phase A to phase B as shown in FIG.12 then the current waveforms are as shown in FIG.13. The reverse signal in phase B shows that there is presence of phase-to-phase fault. According to the asymmetrical fault calculations for the line-to-line fault the current in faulted phases are exactly opposite in magnitude. As also the signal is injected from phase $\mathrm{A}$, therefore it shows reverse signal in the phase $\mathrm{B}$ as fault occurs in between these two phases. To verify it, if we inject signal from phase A then it shows reverse signal in phase $B$.

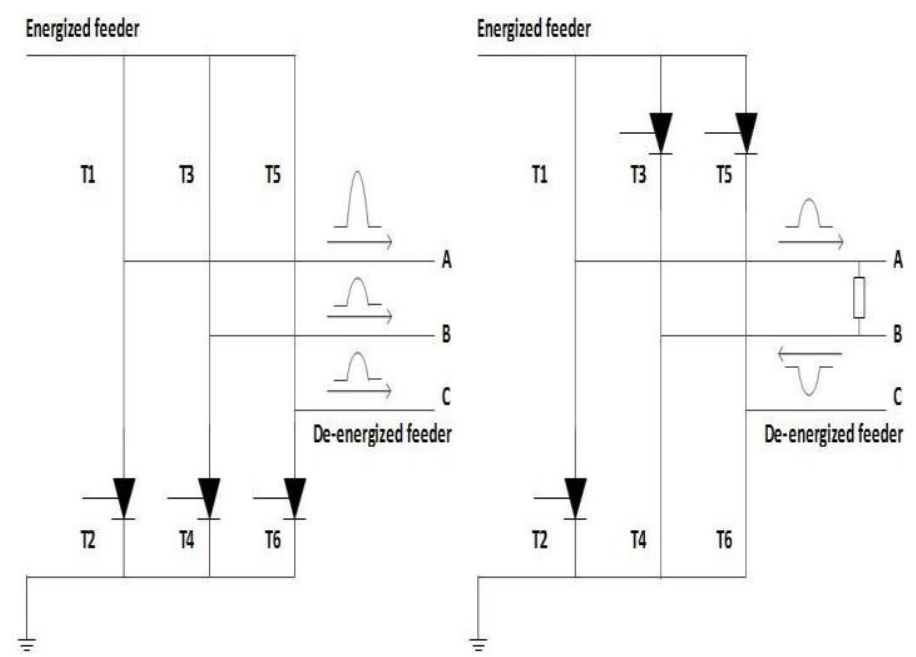

Fig.11 Current waveform with gating control during Phaseto-Ground and Phase-to-Phase fault
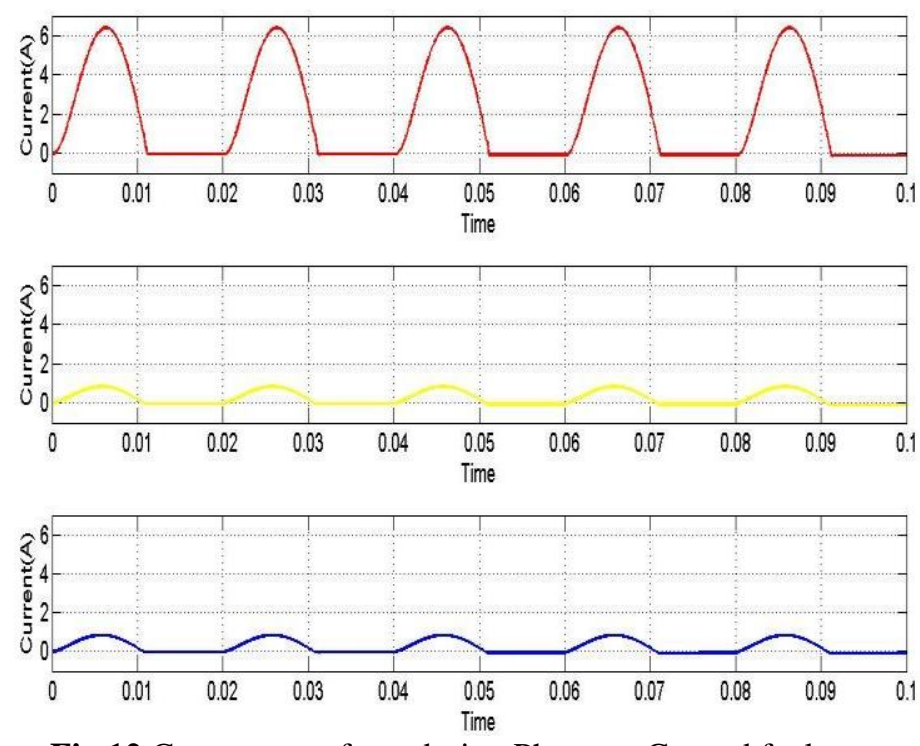

Fig.12 Current waveform during Phase-to-Ground fault
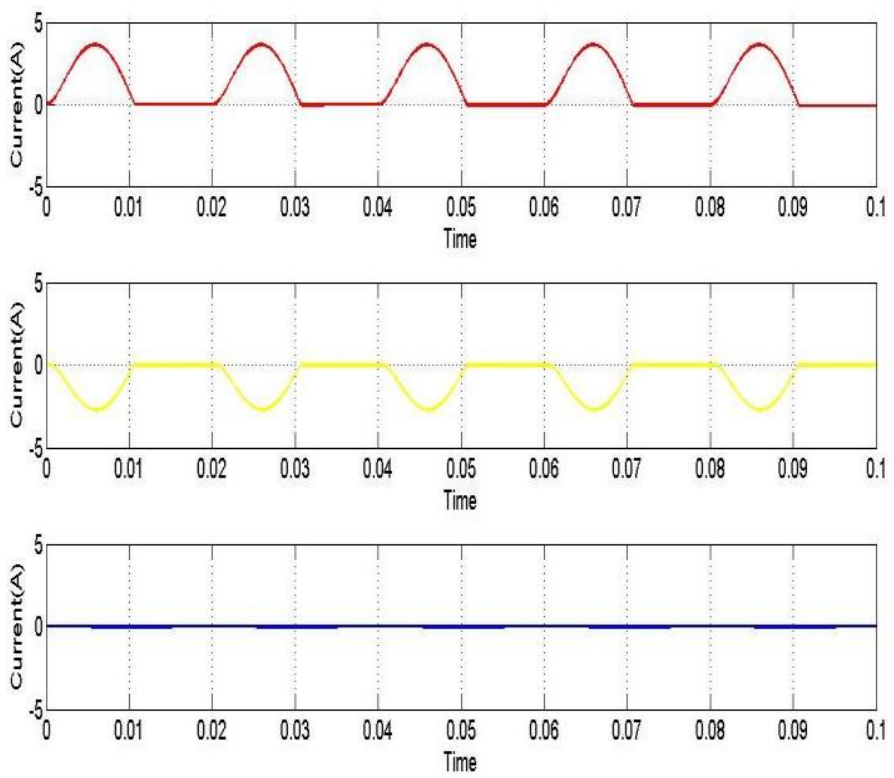

Fig.13 Current waveform during phase-to-phase fault

The fault current in the phase-to-phase fault is depending upon the three parameters such as the fault resistance, load and fault location (line impedance) i.e. the length from fault detection point. For the high fault impedance the current in the phase $\mathrm{B}$ will be reduced.

\section{CONCLUSION}

For detection of fault in the de-energized distribution feeder the thyristor based device is proposed. This device can detect various asymmetrical forms of faults by using only one device. The device connected in parallel to the Recloser can generate a controllable signal and applied it to the downstream line to detect the fault by analyzing the voltage and current waveforms. The signal strength can be adjusted from low to high to detect high impedance faults and to avoid hazards to the downstream devices or personnel. Also it ensures safety reclosing of the feeder. The operation of the thyristor based device is performed in three steps which generally take only few seconds so it is sufficiently fast method to detect fault in de-energized distribution system. In step I, the phase-to-ground faults are detected and in step II and step III, the phase-to-phase faults are detected. We studied the asymmetrical fault analysis and then developed algorithms for detecting the asymmetrical faults in three steps according to the thyristor gating arrangement. The computer simulation is developed in MATLAB to analyze the practical working of the proposed scheme. This technique is used for safety reclosing of the system when system is de-energized for extended period.

\section{ACKNOWLEDGEMENTS}

The authors gratefully acknowledge Wilsun Xu, Yun Wei Li and Xun Long for the valuable work of them on Fault Detection technique in De-Energized Distribution Feeder. Authors are also thankful to Mr. Rajanikant A. Metri and Mr. Pradip D. Bamane for their valuable support. 


\section{REFERENCES}

[1]. "A New Technique to Detect Faults in De-Energized Distribution Feeders-Part I: Scheme and Asymmetrical Fault Detection" Xun Long, Student Member, IEEE, Wilsun Xu, Fellow, IEEE, and Yun Wei Li, Member, IEEE. IEEE TRANSACTIONS ON POWER DELIVERY, VOL. 26, NO 3, JULY 2011

[2]. "A new technique to detect faults in de-energized distribution feeders" Long, Xun, and Yun Wei Li. 2012 IEEE 15th International Conference on Harmonics and Quality of Power, 2012.

[3]. "High impedance fault detection on distribution systems," C. G.Wester, in Proc. Rural Elect. Power Conf., St. Louis, MO, 1998, pp. C5 1-5.

[4]. "An adaptive high and low impedance fault detection method," D. C. Yu and S. H. Khan, IEEE Trans. Power Del., vol. 9, no. 4, pp. 1812-1821, Oct. 1994.

[5]. "Identification of the faulted distribution line using thyristor-controlled grounding," W. Wang, K. Zhu, P. Zhang, and W. Xu, IEEE Trans. Power Del., vol. 24, no. 1, pp. 52-60, Jan. 2009.

[6]. "Cable Tester" A.T.Trihus. U.S. Patent 4254374, Mar. 3, 1981.

[7]. "Adaptive transmission relaying concepts for improved performance," G. D. Rockefeller, C. L. Rockefeller, J. L. Linders, K. L. Hicks, and D.T. Rizy, IEEE Trans. Power Del., vol. 3, no. 4, pp. 1446-1458, Oct. 1988.

[8]. IEEE Guide for Automatic Reclosing of Line Circuit Breakers for AC Distribution and Transmission Lines, IEEE Std C37.104-2002, Apr. 2003.

[9]. "Modern Power System Analysis" Third Edition by D P Kothari, I J Nagrath

[10]. "Elements Of Power System Analysis" by William D Stevenson JR.

\section{BIOGRAPHIES}

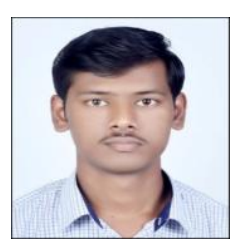

Gajanan Kalidas Vedpathak is the B. Tech Electrical student from Rajarambapu Institute of Technology, Sangli, India. vedpathakgk@gmail.com

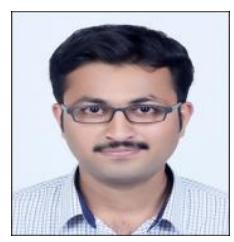

Ajay Ganpati Kashid is the B. Tech Electrical student from Rajarambapu Institute of Technology, Sangli, India. ajaykashid28@gmail.com

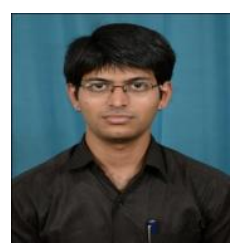

VRSV Bharath Pulavarthi received $M$. Tech degree from Walchand College of Engineering, Sangli, India. Currently, he is an assistant professor at Rajarambapu Institute of Technology, Sangli, India. bharath.pulavarthi@gmail.com 